\title{
The Role of Motivational Teaching Strategies Used by English Language Teachers in Urdu Medium Secondary Schools in Pakistan
}

\author{
Muhammad Asif Saleem ${ }^{1} \&$ Mamuna Ghani ${ }^{1}$ \\ ${ }^{1}$ The Islamia University of Bahawalpur, Pakistan \\ Correspondence: Muhammad Asif Saleem, The Islamia University of Bahawalpur, Pakistan. E-mail: \\ saeedsajid99@gmail.com
}

Received: December 21, 2018 Accepted: January 23, 2019 Online Published: March 2, 2019

doi:10.5539/ijel.v9n2p343

URL: https://doi.org/10.5539/ijel.v9n2p343

\begin{abstract}
A number of strategies are used by English language teachers to get the desired outcomes from the language learners. The strategies prove useful when implemented in accordance with the level of the students and the environment of the L2 classroom. The prime focus of the teachers is to keep the learners motivated in learning English language. This particular research is conducted with the objectives and reasons for which the English teachers in Urdu medium secondary schools and students make use of motivational teaching strategies in their L2 classroom and similarly to indicate the situations where these strategies would be more helpful and crucial. Interview questions were distributed among English teachers and the students of matriculation. They were asked to read the questions and spell comprehensive answers. A comparison is made between the results obtained by the answers of Urdu medium secondary schools' teachers and students. The data were collected and interpreted qualitatively that reflected the views of teachers and students of Urdu medium schools about the use of motivational teaching practices in ELT classroom in relation to students' proficiency of L2 learning.
\end{abstract}

Keywords: motivational teaching strategies, urdu medium secondary schools' teachers and students, ELT classroom, L2 learning

\section{Introduction}

Modern age has seen a phenomenal progress in every sphere of life. Particularly English language has got clear cut top position at international level. In the modern world popularity and need of English as an international language has increased many times as compare to the previous century. The British Council calculations show that English is the second largest language of the world with one billion speakers. The main reason of this wide spread of English is the colonial rule of British in different parts of the world. The two very important reasons of immense popularity of English language are:

- communication mean

- better Job opportunity mean

It is primarily a medium for acquiring higher education and a key factor in obtaining livelihood which is defined as an 'instrumental function of English' (Kachru, 1982).

No doubt English is spoken and understood all over the globe. People of different nationalities can interact through English from every corner of the world with ease. English is very important as it is used as a second language in different countries of the world like Pakistan, India and Bangladesh. In modern world quality of job depends on English a lot. English has become a trade mark of a better job opportunity. A man best at English is considered the best option for the job. English has become the major language of UNO since 1945. Modern researches and inventions are published in English. English is language of science, technology and business. Newspapers and Journals are published in English. English language has prominent work in literary world. There is a lot of work in English literature by non-natives as well.

\subsection{English Language Learning Situation in Pakistan}

Pakistan has five provinces. All provinces have their different languages. Some provinces have more than one language. For example, People of Punjab speak Punjabi, Saraiki and Hindko. Clearly it is a multilingual country. Urdu is a national language of the country. It is spoken and understood in all provinces of the country. But all 
provinces have different regional languages and dialects. This diversity can be observed in social status as well. There are three different social classes in the country i.e., upper class, middle class and lower class. All classes have different approaches to education system according to their status. Elite class or upper class prefers high quality English medium institutions of international level. The middle class and lower class do not have a luxury of higher standard institutions. They are attached to average school systems in terms of teaching strategies, syllabi and evaluation system. These schools use Urdu as a medium of instruction.

Elite class has opportunity of advanced standard schooling in terms of proficiency of teachers, advanced syllabi, modern motivational strategies of teaching and evaluation system. So, there is a wide range of educational institutions which are the best in all respects. These educational institutions use English as a medium of instruction. This diversity in schooling can be observed in students' proficiency as well. There is a clear cut difference between privileged and non-privileged students in terms of proficiency in English language learning. English language is treated as a compulsory subject in Pakistan from class one to BA. English is a dominant second language in offices (Talat, 2002).

\section{Literature Review}

Motivation is a driving force that leads an individual to achieve a set target or goal. It does not matter how much tough the goal is, whatever high the target is, it is motivation that excites, determines and energizes the individual to succeed in every sphere of life. With the passage of time the sources and the factors of motivation change. But it is a concrete fact that motivation is needed through all passage of life. Motivation plays a role of a stone in individual's life that creates thrill in stagnant waters. Last five decades saw an immense development in research on motivation. The research work of Gardner and Lambert (1959), Oxford and Shearin (1994), Crookes and Schmidt (1991), Dörnyei (1994), Ushioda (1996), Noels, Clement and Pelletier (1999), and many other are worth mentioning. All the researchers highlighted the importance of motivation in L2 learning. Hall (2011), declares motivation as a very important factor to achieve a goal. As like other fields of life foreign language learning also depends on motivation a lot. Hall (2011), is of the opinion, "it is difficult to imagine any one learning a language without some degree of motivation" (ibid, p. 134). He states that presence of motivation or absence of motivation plays a role of a very important factor that leads the individual towards success or disappointment. Loewen and Reinders (2011), define motivation as "a psychological construct that refers to the desire and incentive that an individual has to engage in a specific activity". This is a broader definition of motivation that provides a foundation for every field of study. Dörnyei (2005), has limited the concept of motivation to foreign language learning. According to him motivation is an important factor of L2 learning because it is a primary source that initiates foreign language learning and later on keeps learning process tedious. Melendy (2008), suggests motivation as a process in which individual's need and desire are connected to behavior to attain a set goal. Dörnyei (2001), is of the opinion that motivation urges one to initiate and show determination to achieve a set goal to complete the action. Williams and Burden (1997), define motivation as, "a state of cognitive and emotional arousal that leads to a conscious decision to act and gives rise to a period of sustained intellectual and/or physical effort in order to attain a previously set goal or goals". Gardner (2010), calls motivation a complicated and abstract entity that describes behavior.

In the light of above discussions, it is clear that motivation is connected to human behavior and plays a very important role in L2 learning achievement. In context of L2 learning motivation is a very important factor. The researches show that amount of motivation dominates the process of foreign language learning. If the learners are highly motivated the learning process of foreign language will increase at a high rate. Motivation is essence of EFL learning. Foreign language learning is highly dependent on motivation. The definitions of motivation give a solid impression that it is motivation that creates interest in learners and this interest is connected to attitude and behavior of the learner and at the end the previously set target or goal of L2 learning is achieved. In this whole process the role of internal and external factors is very important. In 1990s the role of teacher was considered as one of the most important factors of L2 learning. In this regard research works of Crookes and Schmidt (1991), and Dörnyei (1994), are very important. Dörnyei (1994), suggested the frame work of motivational teaching strategies of $\mathrm{L} 2$ learning. According to him, it is the teacher who creates and maintains the level of interest and determination of students in L2 learning. Gardner (2010), is of the view that some L2 learners are less interested in EFL learning. This point highlights the importance of teacher to create and increase the interest of students in foreign language learning.

In a simple sense it can be said that the vehicle of proficiency of L2 learning gets a high speed with the fuel of motivation. It is teacher who fills the energy in the process of L2 learning. Undoubtedly, the teacher creates the interest, determination, zest and positive behavior of students in ELT classroom. It is clear that teacher is a key factor in having proficiency in L2 learning. 
The development of motivation as a key factor of foreign language learning started with Gardner and Lambert (1959) work on motivation. They are of the view, "an individual acquiring a second language adopts certain behavior patterns which are characteristic of another cultural group and that attitude towards that group will at least partly determine his success at learning a new language" (Gardner \& Lambert, 1959). This definition shows emphasis on motivation as for as second language learning is concerned.

Dörnyei (2005), described three phases of second language learning motivation research. This development in second language learning motivation started with social psychological period (1959-1990), advanced to cognitive situated phase (1990s), and then to process oriented period (2005). It is worth mentioning that L2 motivation research has entered in fourth phase that is called socio dynamic period (2005-present). Self and identity are main focus of socio dynamic phase. All these phases will be discussed in detail in the following section.

Mccombs and Pope (1994), developed the motivational teaching strategies for teachers to use in ELT classroom to improve L2 learning. Schunk (2008) emphasized on the factors that determine L2 motivation like the cognition, personal belief and values. All these factors have been discussed in theories of educational psychology such as expectancy value theory, attribution theory and goal theories.

1990s saw the shift of emphasis from research of L2 motivation to the classroom motivation. Many theorists and researchers formed and developed different motivational teaching strategies to equip the teacher with such forceful techniques that would prove very helpful to initiate and enhance motivation of students in ELT classroom. In this regard the research works of Dörnyei (1994, 2001), Williams and Burden (1997) are relevant and helpful.

\section{Research Methodology}

\subsection{Objectives of the Study}

The current study fulfills the following objectives:

1) To find out the influence of motivational teaching strategies employed by Urdu medium school teachers in L2 settings.

2) To explore the relationship between motivational teaching strategies and the proficiency of Urdu medium students performed in EFL classroom.

3) To make a comparative analysis of motivational teaching strategies used by Urdu medium school teachers and the effect of these motivational teaching strategies on Urdu medium students' performance.

\subsection{Research Questions}

The current study will discuss the following research questions:

1) What is the influence of motivational teaching strategies employed by Urdu medium school teachers in EFL settings?

2) Is there any positive/negative relationship between motivational teaching strategies and the proficiency of Urdu medium students performed in EFL classroom?

3) Is there any relationship between the comparative analysis of motivational teaching strategies used by Urdu medium English school teachers and the effect of these motivational teaching strategies on Urdu medium students' performance?

Interview questions of Appendix A and Appendix B were taken as same from the research work of Eman (2013) on motivational strategies in Saudi Arabian context. Appendix A and Appendix B were consisted of ten and nine questions respectively. Interview questions were distributed among the English teachers and the students of Urdu medium schools. Three teachers of English language from different Urdu medium schools were selected for the research. The students from the similar schools were also selected to make a comparison between the teachers and students about the use of motivational teaching strategies. All the questions were explained to them in detail in order to make them completely understand the questions. The teachers and the students were selected from the local Urdu medium schools of Dera Ghazi Khan Division. They were asked to read the questions and spell comprehensive answers. The responses of the participants assisted the researcher to understand their reactions towards the use of motivational teaching strategies. 


\section{Data Analysis}

\subsection{Interviews of the English Teachers of Urdu Medium Schools}

The current research integrated 03 teachers from different Urdu medium secondary schools who willingly contributed in the research for the interviews. The teachers who contributed in this study were those who had been teaching English at least for the last 10 years. All the teachers who responded in this study were from different language backgrounds.

The answers of all the teachers were reassembled to develop a comprehensive response by combining the similar answers of various teachers into one category. It helped the researcher to cut short the prolonged answers and to get more appropriate results. The combine answers are given below:

\subsubsection{Account of Replies Made by the Teachers}

All the questions asked from the participants are given in Appendix A. This section includes the answers received from the teachers. The answers from various teachers are joined together to make comprehensive and brief statements that help to make the analysis process easy. The answers are:

Answer 1: I think my students feel motivated in English language classroom when I try to motivate my students towards the true importance of English and describe the aims and objectives of learning English.

Answer 2: Yes, being an English teacher I think it is essential that a teacher should use approximately influential activities that can improve English language learning level of students such as an English teacher should practice the technique of generating constructive competition among the schoolchildren.

Answer 3: Being an English teacher I always would like to organize English debate competitions, offer rewards and booties, give my students tasks and responsibilities to encourage them for self-presentation. With the help of these activities my students are motivated and enthused.

Answer 4: At the beginning of language class or task I enthuse a sense of control to the learners, build a threat-free atmosphere and describe the aims, objectives and purposes of teaching and learning of a foreign language.

Answer 5: I usually give my students a reward of motivation by giving admiration for a job well done, and sharing standard work during a task.

Answer 6: An English teacher should offer prospects for success, even the finest schoolchildren can become dejected and demotivated when they feel like they are not receiving the acknowledgment that other students are. An English teacher should make sure that all the learners get chance to play to their strengths and feel involved and esteemed. It can mark a world of difference in their inspiration at the end of the class.

Answer 7: A motivated classroom is one where an English teacher motivates the students towards the interior and exterior usability of English language and he should have the capability to cultivate relationships with his schoolchildren, have persistence, caring, loving and generous nature.

Answer 8: In my personal opinion a demotivated classroom is the classroom where an EFL teacher does not take the pain to offer rewards, does not bother to know about students' interests and does not make high goals for learners.

Answer 9: In my opinion, the most important motivational strategy, especially in the context of Pakistan is that an English language teacher and his learners should focus only English language in EFL classroom.

Answer 10: I am of the view that personally I like joining those activities where a student can play and study at the same time.

\subsection{Students' Interviews}

\subsubsection{Account of Replies Made by the Teachers}

This research is not only confined to the language teachers only but it includes the students from the same institutes too. Similar questions were asked from the selected students. All the answers from various students were sifted to join the similar answers. The answers from different students are combined in single statements to make the answers comprehensive and brief. This process of analyzing all the answers to combine them in one statement further helped to make the analysis process easy. The answers are:

Answer 1: I think I feel motivated in English language classroom when my EFL teacher persuades the students towards the national and international importance of English, describes the objectives of learning and offers different experiences of life. 
Answer 2: Yes, I think it is essential that an EFL teacher should use some persuasive activities that can enhance students' learning level of English language such as an English teacher should use the technique of creating positive competition among the students.

Answer 3: In my opinion an English teacher should organize English debates and speech competitions. Teacher should offer rewards, give students responsibilities and encourage self-presentation. By doing these activities, students will be motivated and enthused and their EFL proficiency will improve.

Answer 4: At the beginning, an EFL teacher should give a sense of control to the students, create a threat-free environment and explain the objectives and purposes of teaching and learning of L2.

Answer 5: An English teacher can give students a reward of motivation by rewarding success publicly, giving admiration for a job well done, and sharing exemplary work during English classroom or during a task.

Answer 6: At the end of the class an English teacher should provide opportunities for success, even the best students can become discouraged and demotivated when they feel like they are not getting the acknowledgment that other students are. An EFL teacher should make sure that all students get an opportunity to play to their strengths and feel included and valued. It can make a world of difference in their motivation at the end of the class.

Answer 7: An EFL teacher should motivate the students toward the internal and external usability of English language and he/she should have the ability to develop relationships with his/her students. He/she must have patience, kind personality, knowledge of learners and dedication towards teaching.

Answer 8: In the context of Pakistan the most important motivational strategies are that a teacher should:

- Offer rewards

- Know students' interests

- Make high goals for learners

- Make things fun

Answer 9: In my opinion, English language teachers and learners should focus only English language in EFL classroom.

\section{Findings and Discussion}

Motivational teaching strategies are the most important as their role in the process of foreign language learning is very significant in the sense that these strategies fasten students' academic activities. Same kind of research works have been done to investigate the perception of teachers and students of similar and different cultures (Guilloteaux \& Dörnyei, 2008; Alshehri, 2013; Papi \& Abdollah Zadeh, 2012). The findings of all these research works advocate the importance of motivational teaching strategies used by EFL teachers to initiate, enhance and maintain the level of students L2 motivation. Findings of the current study also resemble to the study conducted by Hadfield and Dörnyei (2013), they show that motivational activities used by English teachers enhance L2 efficiency. The findings of the current study also reveal that teachers' use of motivational teaching activities expedites the teaching and learning process of foreign language. Teachers offer their strong fundamental belief about motivational teaching strategies and their main focus rests on the socio-academic aspects of their students' life. English teachers show that English language teaching through motivational teaching strategies is supportive in the context of Pakistan because these motivational teaching activities produce positive effects on teachers' as well as their students' understanding of the target language.

Students are highly motivated to get benefit from the use of motivational teaching strategies in EFL classroom by their teachers. The students get help from effective strategies such as to organize English debates and speech competitions, offer rewards, give students responsibilities and encourage self-presentation. By doing these activities, students will be motivated and enthused and their EFL proficiency will improve.

The students also expected that at the beginning of language class or task EFL teachers should give a sense of control to the students, create a threat-free environment and explain the objectives and purposes of teaching and learning of L2. While sharing their experiences about EFL classroom or task they were of the judgment that "their teachers can keep students motivated by rewarding success publicly, giving admiration for a job well done, and sharing exemplary work during English classroom or during a task". Similarly, about the end of task or activity students of Urdu medium schools also expressed a more positive thought and spoke out that "English language teachers should provide opportunities for success, even the best students, can become discouraged and demotivated when they feel like they are not getting the acknowledgment that other students are". The students 
also responded that "offering rewards, knowing students' interests, making high goals for learners are the most important motivational strategies that an English teacher should employ". In the end these students also added that English language teachers should present these strategies in an interesting way so that they would be fruitful for both the stakeholders. Some studies like Anderman and Anderman (2010) focus only English teachers and suggest that teachers should make activities interesting by employing various kinds of tasks which include new and novel components related to the students' interests. Dörnyei (2001), had also indicated a number of activities by which teachers would make a task interesting. This portion strengthens my present study in Pakistani context.

The performance of the students is improved by the effective use of teaching strategies. The main findings of the qualitative data show that both the sections such as Urdu medium schools' English teachers and students are highly motivated and enthused in using motivational teaching strategies in EFL classroom as both the sections' perceptions and viewpoints are closely related to each other. Similarly, after the EFL classroom activity the teachers should frequently assume some motivational teaching strategies or tasks as it is central for English teacher to be watchful about different motivational strategies to inspire students at the end of a task such as the teacher should include activities that lead to the accomplishment of whole group tasks. In the same mode, they were of the judgment that "an encouraged and motivated classroom is one where an English teacher attempts to persuade the students to try harder". The teachers should use English more than $90 \%$ of the time in class so that the students are stimulated to communicate with one another in English. These findings are compatible with the study by Lamb (2012), which suggests that studying English as a compulsory subject with a fixed timetable should maximize the use of the target language. The findings of the research on motivational teaching strategies by Faiza Amir and Yasir Kamal (2011), and Zafar Masaud Muhammad Qasim Ali Mehmood Ul Hassan Saadia Nazli (2015), in Pakistani context also match to the results of current research which show that motivational teaching strategies used in ELT classroom by English language teacher definitely enhance students' L2 learning proficiency.

\section{Conclusion}

The use of effective teaching strategies is highly helpful for the teachers as well as the learners. The English language teachers lacking in use of teaching strategies fail to achieve the required results from the students. The medium of instruction do matter in the teaching of English language. The use of English by the teachers in the class makes the students highly motivated to learn it. The present research also shows that the teachers have positive attitude toward the use of motivational teaching strategies. The analysis of students' answers proves that the use of motivational teaching strategies by their English language teachers is highly helpful to improve their L2 proficiency.

The performance of the students is dependent upon the use of effective teaching strategy by the teacher in the class. The performance of the students enhances when the teachers use motivational strategy by encouraging them to participate in class matters. The students fail to perform well if a discouraging attitude is used by the teacher in the language classroom.

\section{Implications of the Current Study}

The results and findings of the present study have various implications and inferences in the field of L2 teaching and learning.

\subsection{For Urdu Medium Schools' Teachers}

The results and findings of the current study indicate a number of noteworthy inferences and implications that can be protracted and stretched to what non-native EFL teachers do in their L2 situations. The data of the current study emphasized on inclination among the Urdu medium school teachers for the exploration and acceptance of motivational teaching strategies. Therefore, it would be highly recommendable for L2 Urdu medium schools' teachers for achieving greater second language teaching proficiency and ability, Urdu medium schools' teachers may be capable to use the results and outcomes to decrease the amount of root learning activity by the students in EFL classrooms as most of the respondents (teachers) are multilingual and have different linguistic backgrounds; results indicated that a number of teachers used motivational teaching strategies for more than $90 \%$ of the noticeable class time. Consequently, the results of the present study call for EFL Urdu medium schools' teachers training programs to be more alert to actual teaching practices in EFL classrooms. When the non-native EFL teachers are unqualified and unprepared to use the motivational teaching strategies in their L2 teaching, then they develop negative views and attitudes about their appropriateness as English language teachers.

Teacher education and teacher training programs need to bestow with the future English language teachers with suitable classroom motivational strategies, techniques and practices on how to connect motivational teaching 
strategies in L2 classroom. Moreover, by paying some extra attention towards a number of socio-psycholinguistic features that contribute to employ motivational teaching strategies in L2 classrooms, teacher training programs can boost Urdu medium schools' teachers to deal with the common place challenges during the class by using motivational teaching strategies as a teaching device. Identifying these intentions Urdu medium school teachers would be able to adjust their teaching procedures and techniques to help their students to get better L2 learning process in EFL classrooms.

\subsection{For Urdu Medium Students}

The findings and results of the current research offer some noteworthy inferences and implications that can be extended to what the target language learners do in their EFL settings.

For getting improved English language proficiency students may be able to use the results and findings to reduce the use of root learning most frequently they do in EFL classrooms as most of the respondents (students) are multilingual and have linguistic diversity that is why results indicate that the majority of the students are agree and strongly agree that their English teacher should use motivational teaching strategies for different reasons such as to use these activities in L2 atmosphere so as to help them to encourage and support a positive attitude towards L2 learning, to become self-directed and self-sufficient English language learners, to reduce their classroom shock, to facilitate complicated English classroom tasks and to discuss tests and other assignments properly.

\section{Recommendations}

Based on the results and findings of the present study the following recommendations are made.

1) It is highly recommendable for the above-mentioned institution to improve and select the motivational teaching/learning materials that is well-matched to the necessities of the students to develop their proficiency in L2.

2) It is recommended that the School Curriculum Wing should offer syllabus with a variety of L2 motivational strategies, practices and classroom activities for students' better proficiency that can facilitate the learning process.

3) It is furthermore recommended that school education authority should set up a monitoring system to motivate Urdu medium schools' teachers and students to use the target language in EFL classroom.

4) The refresher courses of teachers should be arranged concerning the use of motivational teaching strategies.

5) The teachers of Urdu medium schools should equip themselves with a large number of motivational teaching strategies, skills, knowledge and concepts, so as to be able to recompense the insufficiencies of the English courses which force the students to memorize L2 to get a suitable score.

6) The teachers of Urdu medium schools should employ modern techniques and skills such as computer, multimedia and internet to fulfill the desires of Urdu medium schools' students while learning English as a foreign language.

7) The teachers of Urdu medium schools ought to present supplementary and relevant information by using motivational teaching strategies while teaching English lessons so that students would be able to understand L2 comprehensively.

8) Urdu medium school teachers must boost the motivational level of the students so that they feel more motivated when they start learning L2 in their foreign language classroom.

9) These teachers ought to familiarize the notion of reward and punishment in L2 classroom so as to speed up the process of L2 successfully.

10) Teachers should create student centered classrooms.

11) The students should be provided the basic facilities of classrooms, fans and playgrounds to create a positive environment of L2 learning.

12) The heads of educational institutions should make friendly atmosphere in ELT classrooms.

\subsection{Recommendations for the Future Research Activities}

On the basis of the results and outcomes of the current study, the subsequent recommendations determine possible areas for the future research.

1) The present study was piloted to achieve information from the teachers and students regarding the use of motivational teaching strategies in L2 classroom at secondary level. The same study should be conducted 
with EFL students and teachers at higher secondary, college and university level as well.

2) The current research was conducted in homo and heterogeneous situations regarding the use of motivational teaching strategies in L2 classrooms. The same study should equally be conducted with male and female students separately.

3) This research project was conducted to accumulate facts and figures from the respondents who were teaching and learning compulsory English courses at secondary level but the study should also be conducted on intermediate, graduation or post-graduation level on English as an optional subject.

4) Studies should also be carried on those English courses which are being learnt and taught as Functional English and English for specific purposes.

5) The studies should be done to observe the effect of education of parents, fellow students and backgrounds to judge the language proficiency of learners.

6) The further research can be performed in other divisions of Pakistan to generate more findings concerning the use of motivational strategies in ELT classroom.

7) The present study includes sample from the male teachers teaching the male students if possible research may be conducted to include the sample from the female teachers teaching the female students, the male teachers teaching the female students and the female teachers teaching the male students to generate the evidence regarding the use of motivational teaching strategies in ELT classroom.

\section{References}

Anderman, E. M., \& Anderman, L. H. (2010). Classroom motivation. Upper Saddle River, New Jersey: Merrill.

Crookes, G., \& Schmidt, R. W. (1991). Motivation: Reopening the research agenda. Language Learning, 41(4), 469-512. https://doi.org/10.1111/j.1467-1770.1991.tb00690.x

Dörnyei, Z. (1994). Motivation and motivating in the foreign language classroom. Modern Language Journal, 78(3), 273-284. https://doi.org/10.1111/j.1540-4781.1994.tb02042.x

Dörnyei, Z. (2001a). Motivational strategies in the language classroom. Cambridge: Cambridge University Press. https://doi.org/10.1017/CBO9780511667343

Dörnyei, Z. (2005). The psychology of the language learner: Individual differences in second language acquisition. Mahwah, New Jersey: Lawrence Erlbaum Associates.

Eman, A. A. (2013). Motivational strategies: the perceptions of efl teachers and students in the saudi higher education context. PhD Thesis, University of Salford, Salford, UK.

Faiza, A., \& Yasir, K. (2011). Analysis of Motivational Strategies for Learning of Students on their Performance: A Case of Private Higher Education Institutions of Pakistan. The Dialogue, 6(3).

Gardner, R. C., \& Lambert, W. E. (1959). Motivational variables in second language acquisition. Canadian Journal of Psychology, 13, 266-272. https://doi.org/10.1037/h0083787

Graddle. (1997). The Future of English, A guide to forecasting the popularity of the English language in the 21st century. First published 1997 the British Council 1997, 2000, The digital edition created by The English Company (UK) Ltd.

Gardner, R. C. (2010). Motivation and Second Language Acquisition: The Socio-Educational Model. New York: Peter Long Publishing, Inc.

Guilloteaux, M. J., \& Dörnyei, Z. (2008). Motivating language learners: A classroomoriented investigation of the effects of motivational strategies on student motivation. TESOL Quarterly, 42(1), 55-77. https://doi.org/10.1002/j.1545-7249.2008.tb00207.x

Hall, G. (2011). Exploring English Language Teaching Language in Action. London: Routledge. https://doi.org/10.4324/9780203827840

Hadfield, J., \& Dörnyei, Z. (2013). Motivating learning. Harlow: Longman.

Kachru, B. B. (1982). South Asian English. English as a World Language, 4.

Lamb, M. (2012). A self-system perspective on young adolescents' motivation to learn English in urban and rural settings. Language Learning, 62(4), 997-1023. https://doi.org/10.1111/j.1467-9922.2012.00719.x

Loewen, S., \& Reinders, H. (2011). Key Concepts in Second Language Acquisition. Basingstoke: Palgrave Macmillan. https://doi.org/10.1007/978-0-230-34627-7 
McCombs, B., \& Pope, J. (1994). Motivating hard to reach students. Washington, DC: American Psychological Association. https://doi.org/10.1037/10151-000

Melendy, G. A. (2008). Motivating writers: The power of choice. Asian EFL Journal, 10(3),187-198. Retrieved from http://www.asian-efl-journal.com/September_08_gm.php

Noels, K. A., Clément, R., \& Pelletier, L. G. (1999). Perceptions of teacher communicative style and students' intrinsic and extrinsic motivation. Modern Language Journal, 83(1), 23-34. https://doi.org/10.1111/0026-7902.00003

Oxford, R. L., \& Shearin, J. (1994). Language learning motivation: Expanding the theoretical framework. The Modern Language Journal, 78(1), 12-28. https://doi.org/10.1111/j.1540-4781.1994.tb02011.x

Papi, M., \& Abdollahzadeh, E. (2012). Teacher motivational practice, student motivation, and possible L2 selves: An examination in the Iranian EFL context. Language Learning, 62(2), 571-592. https://doi.org/10.1111/j.1467-9922.2011.00632.x

Schunk, D. H. (2008). Metacognition, self-regulation, and self-regulated learning: Research recommendations. Educational Psychology Review, 20(4), 463-467. https://doi.org/10.1007/s10648-008-9086-3

Talat, M. (2002). The form and function of English in Pakistan. Doctoral dissertation, Bahauddin Zakariya University, Multan. Retrieved from http://prr.hec.gov.pk/thesis/1191.pdf

Ushioda, E. (1996). Developing a dynamic concept of motivation. In T. Hickey \& J. Williams (Eds.), Language, education and society in a changing world (pp. 239-245). Clevedon: Multilingual Matters.

Williams, M., \& Burden, R. (1997). Psychology for language teachers. Cambridge: Cambridge University Press.

Zafar, M., Muhammad, Q. A., Mehmood, U. H., \& Saadia, N. (2015). Comparison of motivational techniques used by elementary school teachers in Pakistan. Journal of Policy Research, 1(1), 1-8. Retrieved from http://rfh.org.pk/jur/magazine-category/jpr

\section{Appendix A}

\section{Teacher interview Questions}

Q1. How can you describe your students' motivation in the English language classrooms?

Q2. Do you think it is important to use motivational strategies to develop students' motivation?

Q3. In your opinion what are the motivational strategies that should be used in language classroom?

Q4. At the beginning of the language class or task, how can you initiate your student's motivation?

Q5. How can you keep your students motivated during the class or during a task?

Q6. At the end of the class or task, what strategies do you use to motivate your students?

Q7. Tell me about a motivated classroom, what do you do to keep them motivated?

Q8. Now, tell me about a demotivated classroom, what do you do to encourage students' motivation?

Q9. What do you think are the most important motivational strategies, especially in the context of Pakistan?

Q10. Do you have anything to add?

\section{Appendix B}

\section{Student interview Questions}

Q1. How can you describe your motivation in the English language classrooms?

Q2. Do you think EFL teachers should use motivational strategies to develop students' motivation?

Q3. In your opinion what are the motivational strategies that should be used in language classroom?

Q4. At the beginning of the language class or task, how can EFL teacher initiate students' motivation?

Q5. During English class or during doing a task, how can a teacher keep students motivated?

Q6. At the end of the class or task, what strategies do a teacher should use to motivate students?

Q7. Tell me about a motivated teacher, what does he/she do to keep you motivated?

Q8. What do you think are the most important motivational strategies, especially in the context of Pakistan?

Q9. Do you have anything to add? 


\section{Copyrights}

Copyright for this article is retained by the author(s), with first publication rights granted to the journal.

This is an open-access article distributed under the terms and conditions of the Creative Commons Attribution license (http://creativecommons.org/licenses/by/4.0/). 